\title{
Contaminants of emerging concern and aquatic organisms: the need to consider hormetic responses in effect evaluations
}

\author{
Evgenios Agathokleous, Damià Barcelón ${ }^{2,3}$, Despo Fatta-Kassinos ${ }^{4}$, Michael N. Moore, ${ }^{5,6,7}$, Edward J. \\ Calabrese $^{8}$ \\ ${ }^{1}$ School of Applied Meteorology, Nanjing University of Information Science and Technology (NUIST), Nanjing 210044, Jiangsu, \\ China. \\ ${ }^{2}$ Institute of Environmental Assessment and Water Research, IDAEA-CSIC, Barcelona 08034, Spain. \\ ${ }^{3}$ Catalan Institute for Water Research, ICRA-CERCA, Girona 17003, Spain. \\ ${ }^{4}$ Department of Civil and Environmental Engineering and NIREAS-International Water Research Center, University of Cyprus, \\ Nicosia 1678, Cyprus. \\ ${ }^{5}$ European Centre for Environment \& Human Health (ECEHH), University of Exeter Medical School, Knowledge Spa, Royal \\ Cornwall Hospital, Truro 5356, UK. \\ ${ }^{6}$ Plymouth Marine Laboratory, Plymouth, Devon 01404, UK. \\ ${ }^{7}$ School of Biological \& Marine Sciences, University of Plymouth, Plymouth 1752, UK. \\ ${ }^{8}$ Department of Environmental Health Sciences, Morrill I, N344, University of Massachusetts, Amherst, MA 01003, USA.
}

Correspondence to: Prof. Evgenios Agathokleous, School of Applied Meteorology, Nanjing University of Information Science and Technology (NUIST), 219 Ningliu Rd., Nanjing 210044, Jiangsu, China. E-mail: evgenios@nuist.edu.cn

How to cite this article: Agathokleous E, Barceló D, Fatta-Kassinos D, Moore MN, Calabrese EJ. Contaminants of emerging concern and aquatic organisms: the need to consider hormetic responses in effect evaluations. Water Emerg Contam Nanoplastics 2021;1:2. https://dx.doi.org/10.20517/wecn.2021.01

Received: 18 Nov 2021 First decision: 13 Dec 2021 Revised: 18 Dec 2021 Accepted: 21 Dec 2021 Published: 26 Dec 2021

Academic Editor: Antonio Ginebreda Copy Editor: Yue-Yue Zhang Production Editor: Yue-Yue Zhang

\begin{abstract}
Contaminants of emerging concern are widespread in the world's waters, raising concerns regarding their effects on living organisms. To evaluate the effects of and predict risks associated with such chemicals, dose-response studies are needed, while the nature of the dose-response relationship is critical for the outcomes of such evaluations. Here, we summarize the literature reporting hormetic responses of aquatic organisms to contaminants of emerging concern. Hormesis is a biphasic dose response encompassing stimulatory responses to low doses and inhibitory responses to high doses. We demonstrate that it occurs widely in numerous aquatic organisms exposed to a wide array of contaminants, including nano/microplastics, suggesting potential effects at
\end{abstract}


doses/concentrations that are considerably lower than the traditional toxicological threshold, which cannot be identified or predicted unless hormesis is considered in the study design. To tackle the effects and associated risks of nano/microplastics and other contaminants on aquatic organisms, hormesis should therefore be taken into account early in the design of studies as well as in relevant risk assessments.

Keywords: Dose-response relationship, ecological effects, ecotoxicological testing, environmental pollution, environmental management, hormesis, regulatory risk assessment, water contaminants

The liquid form of water not only is essential for human health ${ }^{[1]}$ but is also fundamental for carbon-based life, i.e., the form of life on Earth that we currently know ${ }^{[2]}$. Even though two thirds of the surface area of Earth is covered with oceans, only $3 \%$ of the Earth's water is freshwater ${ }^{[3]}$. Furthermore, $99 \%$ of the liquid freshwater represents groundwater, and, thus, only $1 \%$ of the freshwater volume is accessible in lakes, reservoirs, and rivers ${ }^{[3]}$. Seventy percent of freshwater is used for agriculture in most regions of the world ${ }^{[4]}$. An about $60 \%$ increase of food production between the mid-2000s and 2050 will be needed; however, the world's water demand is predicted to increase by $55 \%{ }^{[4]}$. Hence, preserving water quality is of paramount importance for the sustainability of the biosphere.

While numerous chemicals are essential in modern life, their extensive use leads to contamination of the water cycle, which is expected to increase with age, health, growth, and living standards of humans ${ }^{[5]}$. Numerous new chemicals are introduced yearly from industry and commerce as well as from consumption in the urban water $\mathrm{cycle}^{[4]}$. A study estimated that only 330 million people, at most, had access to safe water in China by 2010, and three quarter of the rural water sources were not considered safe by national standards $s^{[6]}$. There are numerous potential sources of water pollution, such as urban streets, suburban development, wastewater treatment plants, factories, croplands, animal feedlots, and rural homes, leading to extensive contamination of natural systems too ${ }^{[4]}$. Water quality and availability are expected to decrease due to climate change, indicating an increased need for reclaimed water from wastewater treatment for multiple purposes, yet effluent treatment is limited in its ability to remove contaminants of emerging concern ${ }^{[5]}$. Therefore, it is profoundly important to understand the effects of such contaminants on living organisms as well as their ecological risks. The assessment of the effects and risks associated with contaminants requires dose-response studies, the outcomes of which depend on the nature of the doseresponse relationship. Hence, this commentary is aimed at summarizing hormetic responses of aquatic organisms to contaminants of emerging concern.

The literature on (eco)toxicological research has been largely framed within a linear-no-threshold (LNT) perspective throughout the 20th century, leading to the wide adoption of the LNT dose-response model by agencies in the United States as well as around the world ${ }^{[7-9]}$. According to the LNT model, chemicalinduced damage increases proportionally to the dose (Figure 1A; hereafter. dose refers to concentration, exposure, or amount unless specified otherwise). LNT assumes that: (1) the damage is cumulative and irreversible; (2) there are no damage-repair mechanisms; (3) organisms lack any capacity to defend and protect themselves against environmental challenges; and (4) each single chemical molecule and the tiniest dose can produce damage up to some extent. The studies upon which the LNT is developed and widely adopted commonly include only few and typically very high doses that are usually environmentally irrelevant.

Along with LNT, the threshold model is one of the two most widely-used dose-response models in the scientific literature and broadly adopted in worldwide regulatory risk assessments for non-carcinogen chemicals of human health concern, and especially for ecological risk assessment ${ }^{[10-12]}$. The threshold model 

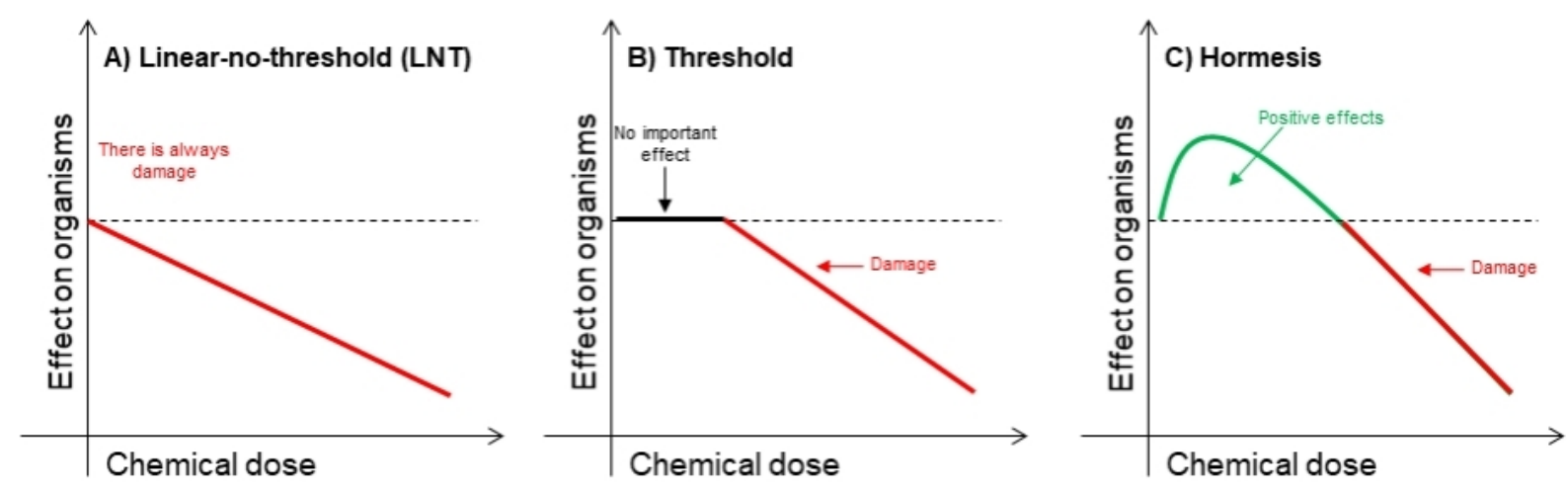

Figure 1. A hypothetical illustration of different dose responses: linear-no-threshold (A); threshold (B); and hormesis (C).

is characterized by an initially null response that extends up to a certain dose, which is considered as the toxicological threshold, and then followed by damage proportionally to dose similarly to the LNT model [Figure $1 \mathrm{~B}$ ]. Any potential effect of doses smaller than the toxicological threshold is attributed to random variance, due to, e.g., measurement, experimental, and/or environmental errors. Conversely to LNT, the threshold model refuses that each single molecule or the tiniest dose induces damage. It also denies the possibility that important responses of organisms can occur at doses smaller than the toxicological threshold.

In the recent years, however, hormesis has been brought into the mainstream of dose response science ${ }^{[13]}$. Hormesis is a dose response that is biphasic in nature, eventually having two distinct phases of responses/effects [Figure $1 \mathrm{C}$ ]. The one phase represents responses that are commonly stimulatory and appears left to the no-observed-adverse-effect-level (NOAEL; toxicological threshold), whereas the other phase depicts negative effects (damage) and appears to the right of the NOAEL. Depending on the endpoint evaluated, it can be U- or J-shaped or their inverse ${ }^{[14]}$. Hormesis suggests that: (1) the damage is cumulative only after a threshold and is reversible; (2) there are damage-repair mechanisms; (3) organisms have the capacity to defend and protect themselves against environmental challenges; and (4) only doses larger than a threshold dose (NOAEL) can produce damage. It is therefore in striking contrast with the LNT model and to a lesser extent with the threshold model.

Hormesis was meant to climb the Hill at Golgotha from early in its inception as a scientific concept due to the - demonstrably incorrect - link with homeopathy, preventing its advancement throughout the 20th century ${ }^{[13]}$. Therefore, hormesis has scientifically matured mainly over the last two decades ${ }^{[13]}$. The current state of the art covers five major advancement areas: (1) documentation of its widespread occurrence and frequency in numerous organisms as a result of exposure to a plethora of chemical agents; (2) understanding of its generalized quantitative features (e.g., typically up to $60 \%$ stimulation) and their independency from the underlying mechanisms, stress-inducing agents, and organisms; (3) development of mathematical models for its statistical evaluation; (4) improvement of the understanding of the underlying mechanisms and potential associated ecological risks; and (5) recognition of its support by ecological and evolutionary theory ${ }^{[13-29]}$.

Hormetic responses induced by aquatic contaminants/pollutants ${ }^{[1]}$ in aquatic organisms have been documented since a long time ago. Pollutants are contaminants occurring at levels that can become hazardous to health and are commonly regulated. Readers may also refer to the Safe Drinking Water Act (https://www.epa.gov/ccl/definition-contaminant) for further information regarding the distinction 
between pollutants and contaminants. For instance, it was in 1981 that Laughlin et al. ${ }^{[30]}$ reported in Science that low concentrations of petroleum hydrocarbons increased megalopal weight in zoeal mud crabs, effects that were opposite to the effects of high concentrations. There was however significant evidence for hormetic responses of aquatic organisms to pollutants earlier, such as the findings of Anthony Stebbing in a clonal hydroid exposed to metals ${ }^{[3,32]}$. Stebbing's work was seminal for the field, especially his 1982 review paper summarizing the hormetic responses of various aquatic and terrestrial organisms to different toxic agents and suggesting its generality ${ }^{[33]}$. It is thus clear that there was significant and broad evidence for this phenomenon since the 1980s. Some 30 years later, a review of the occurrence of hormesis in plants and algae in the literature, based on a database including nearly 700 dose-response curves and mathematical modeling, revealed the occurrence of hormesis in over 50\% of the curves for the herbicides acifluorfen and terbuthylazine and in over $70 \%$ of the curves for glyphosate and metsulfuron-methyl ${ }^{[28]}$.

Today, the evidence of hormesis induced by environmental pollutants and contaminants of emerging concern in aquatic organisms has considerably expanded. For example, a review of the literature concerning the effect of engineered nanomaterials on algae identified 46 hormetic-like dose responses ${ }^{[34]}$. Another detailed review of the published literature revealed an array of studies reporting hormetic responses of various terrestrial and aquatic creatures to micro- and nanoplastics ${ }^{[35]}$, which are also supported by the findings of recent meta-analyses of the effects of microplastics on aquatic organisms, with significant hormetic responses to environmentally realistic concentrations, not only for genotoxicity but also for reproduction endpoints ${ }^{[36,37]}$.

A further survey of the literature for the purpose of this study revealed ample evidence suggestive of hormesis for numerous aquatic organisms and various pollutants and emerging contaminants in dozens of publications, of which only a few selected examples are cited here (older examples can also be traced in the therein references). These examples include a plethora of species, such as of algae (microphytes) ${ }^{[38-49]}$, aquatic flowering plants $s^{[50]}$, organism-attached biofilms $s^{[51]}$, $\operatorname{crustaceans}^{[52-57]}$, cyanobacteria ${ }^{[49,58-61]}$, fishes ${ }^{[22-69]}$, macrophytes ${ }^{[70-75]}$, marine polychaete ${ }^{[76]}$, mollusks (e.g., clams and mussels) ${ }^{[77,78]}$, periphyton ${ }^{[79]}$, phytoplankton $^{[80]}$, sea anemones ${ }^{[8,82]}$, and snails ${ }^{[83]}$. Responses suggestive of hormesis were found for molecular (molecules involved in oxidative stress), cellular (e.g., growth and density), and whole-organism (e.g., growth and body mass) endpoints, as well as endpoints suggesting potential sub-NOAEL effects on organismic interactions, such as via altered feeding activity ${ }^{[83]}$. Such responses were induced by chemicals such as antibiotics/antifungals ${ }^{[38,39,42,45,50,51,67,70,71,75]}$, steroid hormones ${ }^{[41,83]}$, and other human drugs ${ }^{[63,69]}$, bisphenol A and its substitutes ${ }^{[6]]}$, chemical leached from disposed light sticks ${ }^{[5]}$, electroplating processemitted particulate matter ${ }^{[40]}$, effluents from textile-dyeing wastewater treatment plants ${ }^{[46]}$, fullerene crystals $\left(\mathrm{nC}_{60}\right)^{[57]}$, metals and ionic liquids ${ }^{[6,77,81,82]}$, micro/nanoplastics and their leachates ${ }^{[43,44,47,53,60,64,80,84]}$, engineered nanomaterials $s^{[58,59,61,65]}$, pesticides ${ }^{[48,49,52,56,72-74,79,84]}$, phthalic acid esters ${ }^{[78]}$, and polybrominated diphenyl ethers ${ }^{[54]}$. These chemicals include many major contaminants of emerging concern and were applied either individually or jointly, indicating the potential occurrence of hormesis in aquatic organisms exposed to mixtures of such chemicals. Hormetic responses, however, are known to exhibit a significant temporal variation, including overcompensation stimulation, which suggests that a dose-time component needs to be further studied in relation to the response of aquatic organisms to contaminants of emerging concern in the future.

The literature survey and detailed review of the evaluated publications revealed that, in some key studies with findings of hormetic responses, hormesis was not acknowledged, while in other publications hormesis was claimed without sufficient evidence permitting such a conclusion. This suggests that, while hormesis acknowledgement is increased in the aquatic-related literature, there is still room for better understanding 
when it is present and when not. To tackle this issue and facilitate our understanding, it is suggested that researchers who are not immersed into the hormesis literature refer to some key review papers on the topic before drawing absolute conclusions on whether their results reflect hormesis.

In the light of the accumulated evidence for widespread occurrence of hormetic responses across aquatic organisms, hormetic response should be considered when evaluating the effects of micro/nanoplastics and other contaminants of emerging concern on aquatic organisms as well as in ecological risk assessments ${ }^{[85]}$. While the implications of hormetic responses to such contaminants for populations or communities of aquatic organisms are completely unknown, more information about the low-dose, sub-NOAEL effects is needed in order to feed future regulatory risk assessments and enhance the scientific understanding of the underlying mechanisms in aquatic organisms.

The herein analysis also indicates the need for improved research designs that will have the capacity to identify or predict hormetic responses, especially by including a higher number of doses in the sub-NOAEL zone. The maximum stimulation increases by $7 \%$ for each dose additionally included in the sub-NOAEL $z e^{[86]}$, indicating that the number of doses included in the sub-NOAEL zone affects the effect estimates. To minimize error from underestimation of sub-NOAEL effects, a minimum of six doses should be included in the sub-NOAEL zone ${ }^{[86]}$. Care should be exercised to include sub-NAOEL doses differing by orders of magnitude between them. Furthermore, sub-NOAEL responses are modest in amplitude, commonly not greater than $60 \%$ different from the control response ${ }^{[86]}$, which makes their statistical detection difficult ${ }^{[19]}$. Hence, it is important that studies directed to study hormetic responses have robust experimental design with enhanced statistical power, indicating the need for a sufficient number of samples and/or experimental units. Finally, the temporal variation in the hormetic responses indicates the need for multiple assessments over time. The employment of a dependent-samples design with multiple levels could further improve the statistical power.

Although there is a perspective for developing chemicals exhibiting quick and complete degradation in the environment ${ }^{[5]}$, a more rapid degradation in the environment might lead to higher exposures of living organisms due to spontaneously higher levels of bioavailable contaminants. Such spontaneous exposures, whether leading to positive or negative responses of individual organisms, could have unpredicted ecological implications. This exposition, by demonstrating the wide occurrence of responses to sub-NOAEL responses that are also more environmentally realistic, reinforces the need that agendas targeting chemical safety extend to natural ecosystems ${ }^{[87]}$.

\section{DECLARATIONS}

\section{Acknowledgement}

Agathokleous E acknowledges multi-year support from The Startup Foundation for Introducing Talent of Nanjing University of Information Science \& Technology (NUIST), Nanjing, China (No. 003080). Calabrese EJ acknowledges longtime support from the US Air Force (No. AFOSR FA9550-13-1-0047) and ExxonMobil Foundation (No. S18200000000256). The views and conclusions contained herein are those of the authors and should not be interpreted as necessarily representing policies or endorsement, either expressed or implied. Sponsors were not involved in study design, collection, analysis, interpretation, writing, and decision to and where to submit for publication consideration.

\section{Authors' contributions}

Reviewed literature, drafted the manuscript, had a leading role, served as the hub of communication among the authors, and supervised the production of the manuscript: Agathokleous E 
Reviewed the manuscript and contributed intellectual input: Barceló D, Fatta-Kassinos D, Moore MN, Calabrese EJ

Checked and approved the final version for publication: Agathokleous E, Barceló D, Fatta-Kassinos D, Moore MN, Calabrese EJ.

\section{Availability of data and materials}

Not applicable.

\section{Financial support and sponsorship}

None.

\section{Conflicts of interest}

All authors declared that there are no conflicts of interest.

\section{Ethical approval and consent to participate}

Not applicable.

\section{Consent for publication}

Not applicable.

\section{Copyright}

(c) The Author(s) 2021.

\section{REFERENCES}

1. Jéquier E, Constant F. Water as an essential nutrient: the physiological basis of hydration. Eur J Clin Nutr 2010;64:115-23. DOI PubMed

2. Westall F, Brack A. The Importance of water for life. Space Sci Rev 2018:214. DOI PubMed PMC

3. Frappart F. Water and life. Nature Geosci 2013;6:17-17. DOI

4. . UN Environment. Global chemicals outlook II from legacies to innovative solutions: implementing the 2030 agenda for sustainable development. United Nations Environment Programme; 2019.

5. Kümmerer K, Dionysiou DD, Olsson O, Fatta-Kassinos D. A path to clean water. Science 2018;361:222-4. DOI PubMed

6. Yang H, Wright JA, Gundry SW. Water accessibility: boost water safety in rural China. Nature 2012;484:318. DOI PubMed

7. Calabrese EJ. Ethical failings: the problematic history of cancer risk assessment. Environ Res 2021;193:110582. DOI PubMed

8. Calabrese EJ. LNT and cancer risk assessment: Its flawed foundations part 2: how unsound LNT science became accepted. Environ Res 2021;197:111041. DOI PubMed

9. Calabrese EJ. The linear No-Threshold (LNT) dose response model: a comprehensive assessment of its historical and scientific foundations. Chem Biol Interact 2019;301:6-25. DOI PubMed

10. Calabrese EJ, Priest ND, Kozumbo WJ. Thresholds for carcinogens. Chem Biol Interact 2021;341:109464. DOI PubMed

11. Tsatsakis A. Toxicological risk assessment and multi-system health impacts from exposure. Elsevier; 2021. DOI

12. Tsatsakis AM, Vassilopoulou L, Kovatsi L, et al. The dose response principle from philosophy to modern toxicology: the impact of ancient philosophy and medicine in modern toxicology science. Toxicol Rep 2018;5:1107-13. DOI PubMed PMC

13. Agathokleous E, Calabrese EJ. Hormesis: the dose response for the 21st century: the future has arrived. Toxicology 2019;425:152249. DOI PubMed

14. Leak RK, Calabrese EJ, Kozumbo WJ, et al. Enhancing and extending biological performance and resilience. Dose Response 2018;16:1559325818784501. DOI PubMed PMC

15. Erofeeva EA. Environmental hormesis of non-specific and specific adaptive mechanisms in plants. Sci Total Environ 2022;804:150059. DOI PubMed

16. Erofeeva EA. Plant hormesis and Shelford's tolerance law curve. J For Res 2021;32:1789-802. DOI

17. Carvalho MEA, Castro PRC, Azevedo RA. Hormesis in plants under Cd exposure: from toxic to beneficial element? J Hazard Mater 2020;384:121434. DOI PubMed

18. Shahid M, Niazi NK, Rinklebe J, Bundschuh J, Dumat C, Pinelli E. Trace elements-induced phytohormesis: a critical review and mechanistic interpretation. Crit Rev Environ Sci Technol 2020;50:1984-2015. DOI

19. Agathokleous E, Calabrese EJ. A global environmental health perspective and optimisation of stress. Sci Total Environ 2020;704:135263. DOI PubMed

20. Agathokleous E, Calabrese EJ. Hormesis can enhance agricultural sustainability in a changing world. Glob Food Secur 2019;20:150-5. 
DOI

21. Costantini D, Metcalfe NB, Monaghan P. Ecological processes in a hormetic framework. Ecol Lett 2010;13:1435-47. DOI PubMed

22. Costantini D, Monaghan P, Metcalfe NB. Prior hormetic priming is costly under environmental mismatch. Biol Lett 2014;10:20131010. DOI PubMed PMC

23. Costantini D, Borremans B. The linear no-threshold model is less realistic than threshold or hormesis-based models: an evolutionary perspective. Chem Biol Interact 2019;301:26-33. DOI PubMed

24. Costantini D. Hormesis promotes evolutionary change. Dose Response 2019;17:1559325819843376. DOI PubMed PMC

25. Calabrese EJ, Kozumbo WJ. The hormetic dose-response mechanism: Nrf2 activation. Pharmacol Res 2021;167:105526. DOI PubMed

26. Kozumbo WJ, Calabrese EJ. Two decades (1998-2018) of research Progress on Hormesis: advancing biological understanding and enabling novel applications. J Cell Commun Signal 2019;13:273-5. DOI PubMed PMC

27. Calabrese EJ. Hormesis commonly observed in the assessment of aneuploidy in yeast. Environ Pollut 2017;225:713-28. DOI PubMed

28. Cedergreen N, Streibig JC, Kudsk P, Mathiassen SK, Duke SO. The occurrence of hormesis in plants and algae. Dose Response 2006;5:150-62. DOI PubMed PMC

29. Moore MN, Shaw JP, Pascoe C, Beesley A, Viarengo A, Lowe DM. Anti-oxidative hormetic effects of cellular autophagy induced by nutrient deprivation in a molluscan animal model. Mar Environ Res 2020;156:104903. DOI PubMed

30. Laughlin RB Jr, Ng J, Guard HE. Hormesis: a response to low environmental concentrations of petroleum hydrocarbons. Science 1981;211:705-7. DOI PubMed

31. Stebbing ARD. The effects of low metal levels on a clonal hydroid. J Mar Biol Ass 1976;56:977-94. DOI

32. Stebbing A. Hormesis - stimulation of colony growth in Campanularia flexuosa (hydrozoa) by copper, cadmium and other toxicants. Aqua Toxicol 1981;1:227-38. DOI

33. Stebbing A. Hormesis — the stimulation of growth by low levels of inhibitors. Sci Total Environ 1982;22:213-34. DOI PubMed

34. Agathokleous E, Feng Z, Iavicoli I, Calabrese EJ. The two faces of nanomaterials: a quantification of hormesis in algae and plants. Environ Int 2019;131:105044. DOI PubMed

35. Agathokleous E, Iavicoli I, Barceló D, Calabrese EJ. Micro/nanoplastics effects on organisms: a review focusing on 'dose'. J Hazard Mater 2021;417:126084. DOI PubMed

36. Sun T, Zhan J, Li F, Ji C, Wu H. Evidence-based meta-analysis of the genotoxicity induced by microplastics in aquatic organisms at environmentally relevant concentrations. Sci Total Environ 2021;783:147076. DOI PubMed

37. Sun T, Zhan J, Li F, Ji C, Wu H. Effect of microplastics on aquatic biota: a hormetic perspective. Environ Pollut 2021;285:117206. DOI PubMed

38. Li J, Li W, Min Z, Zheng Q, Han J, Li P. Physiological, biochemical and transcription effects of roxithromycin before and after phototransformation in Chlorella pyrenoidosa. Aquat Toxicol 2021;238:105911. DOI PubMed

39. Mao Y, Yu Y, Ma Z, et al. Azithromycin induces dual effects on microalgae: Roles of photosynthetic damage and oxidative stress. Ecotoxicol Environ Saf 2021;222:112496. DOI PubMed

40. Pikula K, Kirichenko K, Vakhniuk I, et al. Aquatic toxicity of particulate matter emitted by five electroplating processes in two marine microalgae species. Toxicol Rep 2021;8:880-7. DOI PubMed PMC

41. Cantalupi A, Maraschi F, Pretali L, et al. Glucocorticoids in freshwaters: degradation by solar light and environmental toxicity of the photoproducts. Int J Environ Res Public Health 2020;17:8717. DOI PubMed PMC

42. Zhang M, Steinman AD, Xue Q, Zhao Y, Xu Y, Xie L. Effects of erythromycin and sulfamethoxazole on Microcystis aeruginosa: Cytotoxic endpoints, production and release of microcystin-LR. J Hazard Mater 2020;399:123021. DOI PubMed

43. Qu H, Ma R, Barrett H, et al. How microplastics affect chiral illicit drug methamphetamine in aquatic food chain? From green alga ( Chlorella pyrenoidosa) to freshwater snail (Cipangopaludian cathayensis). Environ Int 2020;136:105480. DOI PubMed

44. Song C, Liu Z, Wang C, Li S, Kitamura Y. Different interaction performance between microplastics and microalgae: the bioelimination potential of Chlorella sp. L38 and Phaeodactylum tricornutum MASCC-0025. Sci Total Environ 2020;723:138146. DOI PubMed

45. Guo J, Ma Z, Peng J, et al. Transcriptomic analysis of Raphidocelis subcapitata exposed to erythromycin: the role of DNA replication in hormesis and growth inhibition. J Hazard Mater 2021;402:123512. DOI PubMed

46. Cai H, Liang J, Ning XA, Lai X, Li Y. Algal toxicity induced by effluents from textile-dyeing wastewater treatment plants. $J$ Environ Sci (China) 2020;91:199-208. DOI PubMed

47. Chae Y, Kim D, An YJ. Effects of micro-sized polyethylene spheres on the marine microalga Dunaliella salina: focusing on the algal cell to plastic particle size ratio. Aquat Toxicol 2019;216:105296. DOI PubMed

48. Chamsi O, Pinelli E, Faucon B, et al. Effects of herbicide mixtures on freshwater microalgae with the potential effect of a safener. Ann Limnol - Int J Lim 2019;55:3. DOI

49. Zhang Y, Calabrese EJ, Zhang J, Gao D, Qin M, Lin Z. A trigger mechanism of herbicides to phytoplankton blooms: from the standpoint of hormesis involving cytochrome $b_{559}$, reactive oxygen species and nitric oxide. Water Res 2020;173:115584. DOI PubMed

50. Guo X, Liu M, Zhong H, et al. Potential of Myriophyllum aquaticum for phytoremediation of water contaminated with tetracycline antibiotics and copper. J Environ Manage 2020;270:110867. DOI PubMed

51. Guo X, Zhu L, Zhong H, Li P, Zhang C, Wei D. Response of antibiotic and heavy metal resistance genes to tetracyclines and copper in substrate-free hydroponic microcosms with Myriophyllum aquaticum. J Hazard Mater 2021;413:125444. DOI PubMed

52. González-Doncel M, Fernández Torija C, Pablos MV, García Hortigüela P, López Arévalo M, Beltrán EM. The role of PFOS on 
triclosan toxicity to two model freshwater organisms. Environ Pollut 2020;263:114604. DOI PubMed

53. Li Y, Liu Z, Li M, et al. Effects of nanoplastics on antioxidant and immune enzyme activities and related gene expression in juvenile Macrobrachium nipponense. J Hazard Mater 2020;398:122990. DOI PubMed

54. Liu Y, Guo R, Tang S, et al. Single and mixture toxicities of BDE-47, 6-OH-BDE-47 and 6-MeO-BDE-47 on the feeding activity of Daphnia magna: From behavior assessment to neurotoxicity. Chemosphere 2018;195:542-50. DOI PubMed

55. Cesar-Ribeiro C. Chemical contents of disposed light sticks affect the physiology of rocky crab Pachygrapsus transversus and gray shrimps Litopennaeus vanammei. Bull Environ Contam Toxicol 2021;107:370-7. DOI PubMed

56. Bordin ER, Cesar Munhoz R, Panicio PP, Freitas AM. Transgenerational effects of environmentally relevant concentrations of atrazine and glyphosate herbicides, isolated and in mixture, to freshwater microcrustacean Daphnia magna. Res $S q$ 2021. DOI

57. Wang P, Ng QX, Zhang B, et al. Employing multi-omics to elucidate the hormetic response against oxidative stress exerted by $\mathrm{nC}_{60}$ on Daphnia pulex. Environ Pollut 2019;251:22-9. DOI PubMed

58. Xu K, Li Z, Juneau P, et al. Toxic and protective mechanisms of cyanobacterium Synechocystis sp. in response to titanium dioxide nanoparticles. Environ Pollut 2021;274:116508. DOI PubMed

59. Wu S, Ji X, Li X, et al. Mutual impacts and interactions of antibiotic resistance genes, microcystin synthetase genes, graphene oxide, and Microcystis aeruginosa in synthetic wastewater. Environ Sci Pollut Res Int 2021. DOI PubMed

60. Wan Q, Li J, Chen Y. Comparative growth and cellular responses of toxigenic Microcystis exposed to different types of microplastics at various doses. Environ Pollut 2021;290:117950. DOI PubMed

61. Zuo S, Yang H, Jiang X, Ma Y. Magnetic $\mathrm{Fe}_{3} \mathrm{O}_{4}$ nanoparticles enhance cyanobactericidal effect of allelopathic p-hydroxybenzoic acid on Microcystis aeruginosa by enhancing hydroxyl radical production. Sci Total Environ 2021;770:145201. DOI PubMed

62. Biswas S, Bellare J. Adaptive mechanisms induced by sparingly soluble mercury sulfide ( $\mathrm{HgS})$ in zebrafish: behavioural and proteomics analysis. Chemosphere 2021;270:129438. DOI PubMed

63. Constantine LA, Green JW, Schneider SZ. Ibuprofen: fish short-term reproduction assay with Zebrafish (Danio rerio) based on an extended OECD 229 protocol. Environ Toxicol Chem 2020;39:1534-45. DOI PubMed

64. Ding J, Zhang S, Razanajatovo RM, Zou H, Zhu W. Accumulation, tissue distribution, and biochemical effects of polystyrene microplastics in the freshwater fish red tilapia (Oreochromis niloticus). Environ Pollut 2018;238:1-9. DOI PubMed

65. Ding Y, Yang Y, Chen J, Chen H, Wu Y, Jin L. Toxic effects of ZnSe/ZnS quantum dots on the reproduction and genotoxiticy of rare minnow (Gobiocypris rarus). Comp Biochem Physiol C Toxicol Pharmacol 2021;247:109065. DOI PubMed

66. Fan X, Hou T, Jia J, Tang K, Wei X, Wang Z. Discrepant dose responses of bisphenol A on oxidative stress and DNA methylation in grass carp ovary cells. Chemosphere 2020;248:126110. DOI PubMed

67. Han Y, Ma Y, Yao S, Zhang J, Hu C. In vivo and in silico evaluations of survival and cardiac developmental toxicity of quinolone antibiotics in zebrafish embryos (Danio rerio). Environ Pollut 2021;277:116779. DOI PubMed

68. Jin M, Dang J, Paudel YN, et al. The possible hormetic effects of fluorene-9-bisphenol on regulating hypothalamic-pituitary-thyroid axis in zebrafish. Sci Total Environ 2021;776:145963. DOI PubMed

69. Pandelides Z, Thornton C, Lovitt KG, et al. Developmental exposure to $\Delta^{9}$-tetrahydrocannabinol (THC) causes biphasic effects on longevity, inflammation, and reproduction in aged zebrafish (Danio rerio). Geroscience 2020;42:923-36. DOI PubMed PMC

70. Alkimin GD, Santos J, Soares AMVM, Nunes B. Ecotoxicological effects of the azole antifungal agent clotrimazole on the macrophyte species Lemna minor and Lemna gibba. Comp Biochem Physiol C Toxicol Pharmacol 2020;237:108835. DOI PubMed

71. Liu Y, Pang Y, Yang L, Ning S, Wang D, Wu Z. Responses of Hydrocharis dubia (B1.) Backer and Trapa bispinosa roxb. to tetracycline exposure. Ecotoxicol Environ Saf 2020;202:110890. DOI PubMed

72. Peres L, Della Vechia J, Cruz C. Hormesis effect of herbicides subdoses on submerged macrophytes in microassay conditions. Planta daninha 2017:35. DOI

73. Di Baccio D, Pietrini F, Bertolotto P, et al. Response of Lemna gibba L. to high and environmentally relevant concentrations of ibuprofen: Removal, metabolism and morpho-physiological traits for biomonitoring of emerging contaminants. Sci Total Environ 2017;584-585:363-73. DOI PubMed

74. Farooq N, Abbas T, Tanveer A, et al. Differential hormetic response of fenoxaprop-p-Ethyl resistant and susceptible phalaris minor populations: a potential factor in resistance evolution. Planta daninha 2019;37:e019187554. DOI

75. Hu H, Zhou Q, Li X, et al. Phytoremediation of anaerobically digested swine wastewater contaminated by oxytetracycline via Lemna aequinoctialis: nutrient removal, growth characteristics and degradation pathways. Bioresour Technol 2019;291:121853. DOI PubMed

76. Liu F, Lu Z, Wu H, Ji C. Dose-dependent effects induced by cadmium in polychaete Perinereis aibuhitensis. Ecotoxicol Environ Saf 2019;169:714-21. DOI PubMed

77. Zhan J, Wang S, Li F, Ji C, Wu H. Dose-dependent responses of metabolism and tissue injuries in clam Ruditapes philippinarum after subchronic exposure to cadmium. Sci Total Environ 2021;779:146479. DOI PubMed

78. Xu H, Cao W, Sun H, et al. Dose-dependent effects of Di-(2-Ethylhexyl) phthalate (DEHP) in mussel Mytilus galloprovincialis. Front Mar Sci 2021;8:658361. DOI

79. Vera MS, Trinelli MA. First evaluation of the periphyton recovery after glyphosate exposure. Environ Pollut 2021;290:117998. DOI PubMed

80. Mao Y, Ai H, Chen Y, et al. Phytoplankton response to polystyrene microplastics: Perspective from an entire growth period. Chemosphere 2018;208:59-68. DOI PubMed

81. Ianna ML, Reichelt-Brushett A, Howe PL, Brushett D. Application of a behavioural and biochemical endpoint in ecotoxicity testing with Exaiptasia pallida. Chemosphere 2020;257:127240. DOI PubMed 
82. Howe PL, Reichelt-Brushett AJ, Clark MW. Development of a chronic, early life-stage sub-lethal toxicity test and recovery assessment for the tropical zooxanthellate sea anemone Aiptasia pulchella. Ecotoxicol Environ Saf 2014;100:138-47. DOI PubMed

83. Svigruha R, Fodor I, Padisak J, Pirger Z. Progestogen-induced alterations and their ecological relevance in different embryonic and adult behaviours of an invertebrate model species, the great pond snail (Lymnaea stagnalis). Environ Sci Pollut Res Int 2021;28:59391402. DOI PubMed PMC

84. Nong QY, Liu YA, Qin LT, et al. Toxic mechanism of three azole fungicides and their mixture to green alga Chlorella pyrenoidosa. Chemosphere 2021;262:127793. DOI PubMed

85. Agathokleous E, Barceló D, Calabrese EJ. US EPA: is there room to open a new window for evaluating potential sub-threshold effects and ecological risks? Environ Pollut 2021;284:117372. DOI PubMed

86. Calabrese EJ, Agathokleous E, Kozumbo WJ, Stanek EJ 3rd, Leonard D. Estimating the range of the maximum hormetic stimulatory response. Environ Res 2019;170:337-43. DOI PubMed

87. Rohr JR, Salice CJ, Nisbet RM. Chemical safety must extend to ecosystems. Science 2017;356:917. DOI PubMed 